\title{
Aipan: An Inspiring Folkart for Textile Designing
}

\author{
Vandana Bhandari $^{1 *}$, Anita Rani ${ }^{2}$, Manisha Gahlot ${ }^{3}$ and Sakshi ${ }^{4}$ \\ Department of Clothing and Textiles, College of Home Science, G.B.P.U.A.T., \\ Pantnagar, Uttarakhand, India \\ *Corresponding author
}

\section{A B S T R A C T}

\section{Keywords}

Aipan, Folk art,

Border

arrangements

Article Info

Accepted:

07 May 2019

Available Online:

10 June 2019

\begin{abstract}
India, the land of rich cultural heritage, has been known to the world for its vibrant arts and crafts since ancient time. Floor paintings are one of these art forms which are ritualistic part of ancient Indian culture. Aipan is one of the traditional folk arts of Kumaun region of Uttarakhand drawn on the floor, walls, etc. in the house. In the present study, aipan designs were explored for the designing of woven borders. Ten aipan designs (5 symmetrical and 5 asymmetrical in form) were selected from secondary sources and adapted to make them suitable for use in weaving. Taking each design, four different border arrangements were developed using computer software Corel Draw X7. The prepared border arrangements were assessed by a panel of 30 judges. The selected borders were converted into graphic form establish their suitability for use in weaving using extra yarn figuring technique. This effort was also an attempt to preserve the ancient and valuable art of the state in form of tangible textile base.
\end{abstract}

\section{Introduction}

Indian art history has rich store of traditional arts and folk paintings from ancient times to present times. Hand spun and hand woven textiles are the oldest arts originated in India and evidences revealed the existence of finely woven and madder dyed textiles found at Mohenjo-Daro of Indus valley civilization (Gillow and Barnard, 1991). These arts and crafts reflect rich heritage of India through beautiful designs inspired from monuments, religion, nature, etc. Indian arts and crafts had attracted not only the people of India since ancient times but also have a huge global demand in present times (Kumari, 2013).
Various crafts have been used to develop designs suitable for textile applications.

Aipan is a folk art of Kumaun region of Uttarakhand which is related to Hindu myths and rituals. It is the art for floor decoration which has sustained till date because of its religious, social and cultural significance (Sah, 2005). The aipan designs are inspired from the geometric patterns, natural figures of real objects, symbolic designs referring to God and goddesses, etc. It is drawn in front courtyard, entry points at doors, walls, papers and at places of worship. This art form has been explored by different researchers for development of design suitable for textile 
designing through weaving (Sangama and Rani, 2012; Kumari, 2013 and Arya et al., 2017), tie and dye (Negi et al., 2017), screen printing (Arya et al., 2012 and Arya et al., 2011), embroidery (Singh et al., 2013), and appliqué (Negi et al., 2015 and Negi and Rani, 2016).

Borders are used as effective trim in garments as well as home textiles. These borders are embellished with embroidery, sequins, beads, printing, etc. Use of border can make a plain fabric stylish and attractive to the consumer. Borders are possibly the oldest method of embellishment. Rig veda also reveals the use of shining gold wraps and fabrics with pearl woven borders (Bhatnagar, 2005). Designing of the borders suitable for technique of weaving would be an innovative approach towards value addition of existing products with aipan designs at one end and on other hand woven borders would diversify product range being available in the state. The woven borders would add variety to the existing borders designs in the market. These types of borders would attract the consumers who have inclination towards traditional folk art. Thus this attempt would help to preserve the heritage of the state.

\section{Materials and Methods}

The aim of the study was to create a design pool, by the adaption of Aipan designs of Kumaun region for development woven border using extra yarn figuring technique of weaving.

\section{Collection and selection of aipan designs}

Different secondary sources like books, cards, sticker, and internet images, etc. were explored to collect thirty distinct and decorative designs from famous folk art form i.e., Aipan of Utttarakhand. From the collected designs, ten designs were selected which were found representative to culture of Kumaun region of Uttarakhand.

\section{Adaptation of aipan designs}

These selected ten designs were adapted individually to make them suitable for incorporation into textile structure through weaving. The adaptation of selected designs was done through use of Corel Draw X7 software.

The adaptation process involved use tools present in edit menu of the software. The select tool, bezier tool, shape tool, etc. were used to alter the lines of the design to make it suitable for weaving. From these ten designs five were symmetrical and five were asymmetrical in from.

\section{Development of border arrangements and their selection}

The method given by Gahlot and Naik (2014) was used to prepare border arrangements using ten adapted designs. The border arrangements were prepared with arrangements depicted by notations viz., $\mathrm{P}_{111}, \mathrm{P}_{112}, \quad \mathrm{P}_{1 \mathrm{a} 1}$ and $\mathrm{P}_{1 \mathrm{~m} 1}$ for symmetrical designs while the asymmetrical designs were placed in border arrangements designated by notations namely, $\mathrm{P}_{111}, \mathrm{P}_{\mathrm{m} 11}, \mathrm{P}_{112}$, and $\mathrm{P}_{1 \mathrm{a} 1}$ (Table 1).

These border arrangements were prepared with the help of Corel DRAW X7 software using the required actions. The prepared border arrangements were evaluated by a panel of thirty judges including faculty members, M.Sc. and Ph.D. students from Department of Clothing and Textiles and Department of Family Resource Management, College of Home Science, G. B. P. U. A. \& T., Pantnagar. The judges assigned ranks to the border arrangements on the basis of their overall appearance. The most preferred 
arrangement was given rank I was used for developing colour combinations in each border type (as per notations).

Development of colour combination for selected border arrangements and their selection

The selected border arrangements were replicated using two colour schemes namely monochromatic colour scheme (primary colours - red, blue and yellow) and complementary colour scheme (red-green, blue-orange and yellow-violet). Six colour combinations were made for 10 selected border arrangements using complementary colours i.e., total sixty colour combinations were prepared for selected border arrangements. The selected border arrangements in different colour combinations were evaluated by the same panel of judges. The judges evaluated each colour combination used in borders on five point rating scale on the basis of overall appearance and finally one colour scheme was selected for each design.

\section{Results and Discussion}

\section{Aipan Designs and their description}

Total 10 designs were selected from 30 collected aipan designs on the basis of their significance in day to day life; on basis of their representation of Kumauni culture and their suitability for weaving technique. The 10 selected designs were classified into symmetrical and asymmetrical designs and were adapted using computer software Corel DRAW X7.

The 5 symmetrical aipan designs were laxmi pau, ghanti, phani, nata and bada himanchal. These designs had symmetry on either side of vertical centre line. While ghiroli 1, ghiroli 2, sua, shankhi and chameli patia were asymmetrical aipan designs as these were not symmetric. The selected and adapted designs are given in Table 2.

The description of the 10 selected aipan designs is as follows:

\section{Laxmipau}

This aipan design has been enthused from the footprint of the Goddess Laxmi. This is a stylised design and is used in both the styles of floor paintings i.e., creeper and worshiping seat. On Diwali festival, this motif is essentially drawn at the main entrance of the house and at different places in Mahalaxmi chowki.

\section{Ghanti}

This is a stylised design which has been derived from the bell (ghanti) used during prayers in Hindu temples and in other cultural rituals or pooja. Ghanti motif is drawn in floors as well as on the paper. It is essentially drawn in Surya chowki as asan used for the worshipping of Sun God during naamkaran ceremony of newborn and in the Khodas chowki over the ceremonial cloth like pichora.

\section{Phani}

This is the stylised version of snake's hood and it symbolises the Lord Shiva. This design is found drawn on the paper or cloth in the form of creeper which is used during worship on Nag Panchami.

\section{Nata}

This is a figurative style of aipan which is drawn on the walls of the dining room which is considered as temple in household where the basic need of life i.e., food is fed to the people. The figures used in nata represent the 
Goddess of wealth, Laxmi and God of wellbeing and protection, Narayan. This geometric design is widely drawn on the walls of dining room on Diwali festival.

\section{Bara Himanchal}

This is a stylised design used in aipan and has been derived from the highest snow covered region of Himalaya. It symbolizes a metallic pitcher used in household of Kumaun region to store water. This design is drawn in both the styles of floor painting i.e., creepers as well as worshiping seats. This design is essentially drawn in Maatrika Chowki during all auspicious events and worshipping of Gods.

\section{Ghiroli}

This design has been enthused from a small sized reptile having 4 legs locally known as ghiroli. This is a stylised design which is drawn in creepers and chowkies (Saraswati chowki, Mahalaxmi chowki, Dhuliargha chowki, etc.) used during pujas and festivals. Two types of ghiroli designs i.e. ghiroli 1 and ghiroli 2 were selected in this study.

\section{Sua}

This is a stylised design is inspired from parrot which is locally known as sua in Kumaun region. This design is associated with the arrival of beloved ones and hence is drawn on the floor in form of creeper as well as chowki during festivals and religious occasion. It is essentially drawn in Vivah chowki.

\section{Shankhi}

This stylized design has its origin from the counch shell which is associated with the creation of first sound, Om. It is also considered a symbol of purity and auspiciousness. This is drawn on the chowkies as well on the paper and cloth. It is essentially drawn in the Khodas chowki used on ceremonial veil, pichhora worn by women during all religious events and in Surya chowki drawn on wood used during naamkaran ceremony of newborn.

\section{Chameli patia}

This is stylised design inspired from the jasmine flower which symbolises the purity. It is used in both styles of floor paintings (creepers and chowkies). This design is commonly drawn in Saraswati chowki during worship and Dhuli Argha chowki during marriage ceremony.

\section{Selected border arrangements}

One border arrangement of each adapted aipan design was selected on the basis of response for overall appearance. The weighted mean scores (WMS) of each border arrangement is given in Table 3 . The value of WMS for all the arrangements was found above half the value of highest possible WMS i.e., 4.00 which represents good level of acceptability of the designs among panel members.

The selected border arrangements were replicated in planned colour schemes and were evaluated again by 30 judges to select one border arrangement in colour.

The selected colour schemes for each design are given in the Table 4 . The value of WMS for all the arrangements represents good level of acceptability of the designs among panel members.

These selected border arrangements in different colour schemes can be woven by using extra yarn figuring technique of weaving with background in any basic weave like plain weave, twill, satin and their 
variation using graphs of design. Various interlacement etc. can be utilised for the techniques of figuring like floating, weaving.

Table.1 Description of border arrangements possible with single design

\begin{tabular}{|c|c|c|c|}
\hline Sl. No. & $\begin{array}{c}\text { Notation of } \\
\text { border }\end{array}$ & Description of border arrangements & $\begin{array}{l}\text { Design geometry used } \\
\text { in border } \\
\text { arrangement }\end{array}$ \\
\hline 1. & $\mathrm{P}_{111}$ & $\begin{array}{l}\text { Translation left alone: Border arrangement } \\
\text { having no vertical reflection, no horizontal } \\
\text { reflection and no rotation only translation of } \\
\text { designs }\end{array}$ & Translation (repetition) \\
\hline 2. & $\mathrm{P}_{\mathrm{m} 11}$ & $\begin{array}{l}\text { Mirror galore: Border arrangement having } \\
\text { vertical reflection only no horizontal reflection, } \\
\text { no glide reflection and no rotation }\end{array}$ & Vertical reflection \\
\hline 3. & $\mathrm{P}_{112}$ & $\begin{array}{l}\text { Flip over: Border arrangement having rotation } \\
\text { of designs, no vertical reflection, no horizontal } \\
\text { reflection and no glide reflection. }\end{array}$ & Rotation \\
\hline 4. & $\mathrm{P}_{1 \mathrm{a} 1}$ & $\begin{array}{l}\text { Footsteps: Border arrangement with glide } \\
\text { reflection of designs and no rotation, no } \\
\text { horizontal reflection, no vertical reflection. }\end{array}$ & Glide reflection \\
\hline 5. & $\mathrm{P}_{1 \mathrm{~m} 1}$ & $\begin{array}{l}\text { Only one mirror: Border arrangement having } \\
\text { horizontal reflection and no vertical reflection, } \\
\text { no glide reflection, no rotation }\end{array}$ & Horizontal reflection \\
\hline
\end{tabular}


Table.2 Selected and adapted aipan designs

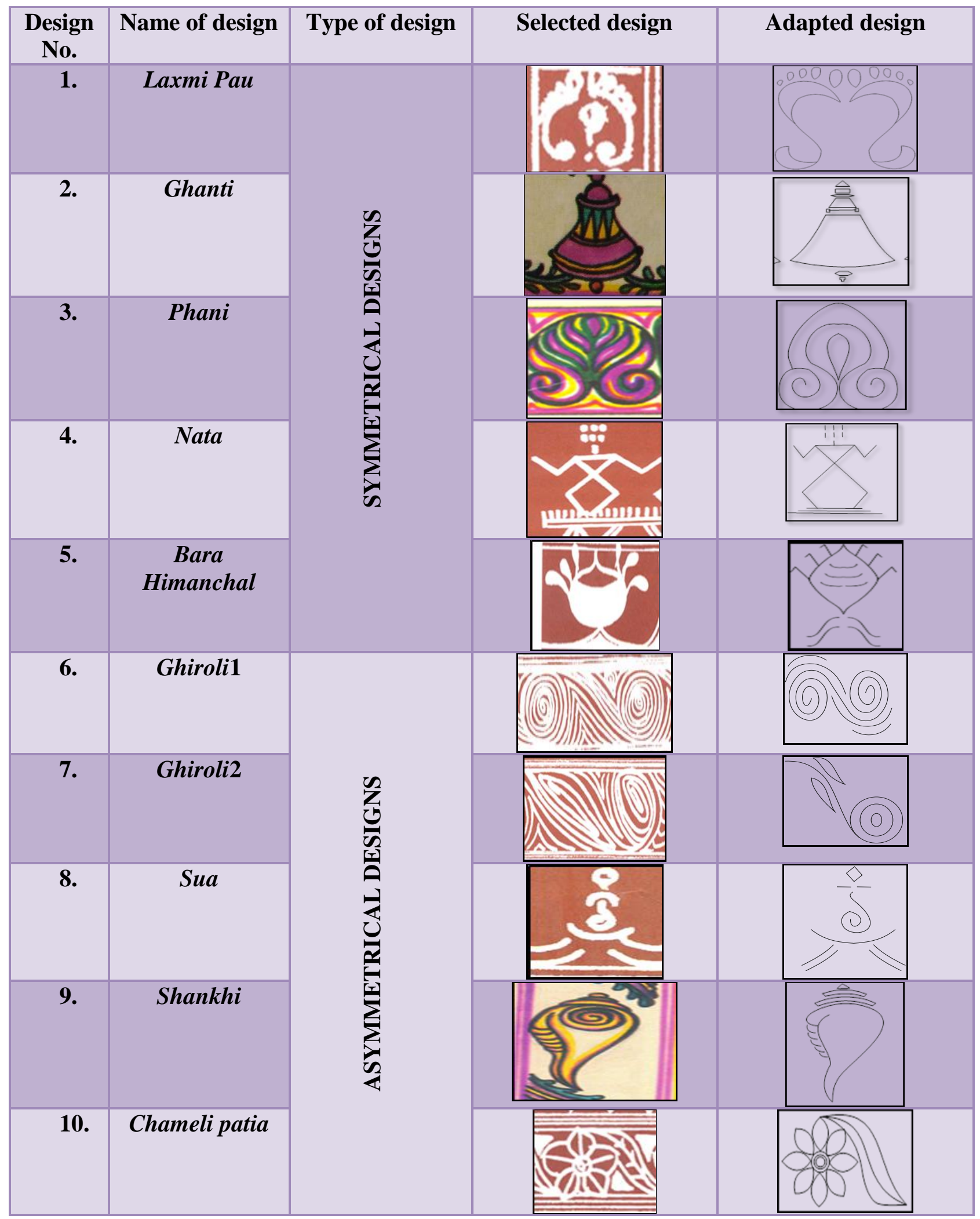


Int.J.Curr.Microbiol.App.Sci (2019) 8(6): 527-537

Table.3 The weighted mean scores of each border arrangement $n=30$

\begin{tabular}{|c|c|c|c|c|c|c|c|}
\hline $\begin{array}{c}\text { Type } \\
\text { of } \\
\text { design }\end{array}$ & $\begin{array}{c}\text { Design } \\
\text { No. }\end{array}$ & $\begin{array}{c}\text { Border } \\
\text { Arrangeme } \\
\text { nts }\end{array}$ & $\begin{array}{c}\text { Weighted } \\
\text { Mean } \\
\text { Score }\end{array}$ & $\begin{array}{l}\text { Type of } \\
\text { design }\end{array}$ & $\begin{array}{c}\text { Design } \\
\text { No. }\end{array}$ & $\begin{array}{c}\text { Border } \\
\text { Arrangeme } \\
\text { nts }\end{array}$ & $\begin{array}{c}\text { Weighted } \\
\text { Mean } \\
\text { Score }\end{array}$ \\
\hline \multirow{20}{*}{ 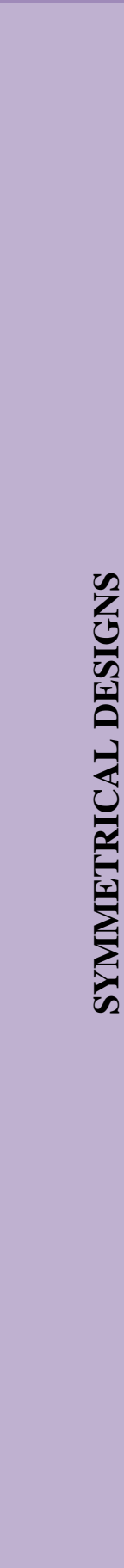 } & \multirow[t]{4}{*}{1} & $\mathbf{P}_{111}$ & 2.13 & \multirow{20}{*}{ 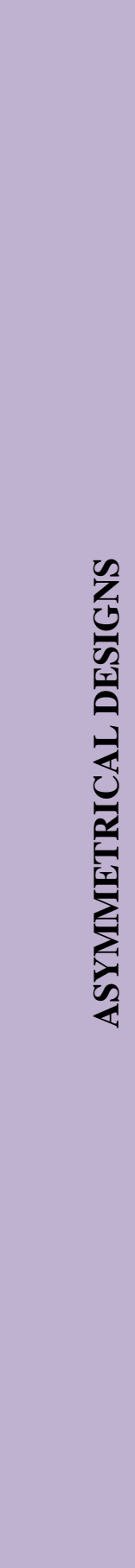 } & \multirow[t]{4}{*}{6} & $\mathbf{P}_{111}$ & 2.63 \\
\hline & & $\mathbf{P}_{112}$ & 2.26 & & & $\mathbf{P}_{\mathrm{m} 11} *$ & 2.93 \\
\hline & & $\mathbf{P}_{1 \mathrm{a} 1}$ & 2.03 & & & $P_{112}$ & 2.50 \\
\hline & & $\mathbf{P}_{1 \mathrm{~m} 1} *$ & 2.90 & & & $\mathbf{P}_{1 \mathrm{a} 1}$ & 2.16 \\
\hline & \multirow[t]{4}{*}{2} & $\mathbf{P}_{111}$ & 2.50 & & \multirow[t]{4}{*}{7} & $\mathbf{P}_{111} *$ & 2.73 \\
\hline & & $P_{112}$ & 2.56 & & & $P_{\mathrm{m} 11}$ & 2.70 \\
\hline & & $\mathbf{P}_{1 \mathrm{a1}}$ * & 2.83 & & & $P_{112}$ & 2.60 \\
\hline & & $\mathbf{P}_{1 \mathrm{~m} 1}$ & 2.26 & & & $\mathbf{P}_{1 \mathrm{a} 1}$ & 2.10 \\
\hline & \multirow[t]{4}{*}{3} & $P_{111}$ & 2.16 & & \multirow[t]{4}{*}{8} & $P_{111}$ & 2.50 \\
\hline & & $P_{112}$ & 2.16 & & & $\mathbf{P}_{\mathrm{m} 11} *$ & 2.96 \\
\hline & & $\mathbf{P}_{1 \mathbf{1} 1}$ & 2.76 & & & $\mathbf{P}_{112}$ & 2.00 \\
\hline & & $\mathbf{P}_{1 \mathrm{~m} 1} *$ & 3.03 & & & $\mathbf{P}_{1 \mathrm{a} 1}$ & 2.70 \\
\hline & \multirow[t]{4}{*}{4} & $\mathbf{P}_{111}$ & 2.40 & & \multirow[t]{4}{*}{9} & $\mathbf{P}_{111}$ & 2.00 \\
\hline & & $\mathbf{P}_{112}$ & 2.26 & & & $P_{m 11} *$ & 2.90 \\
\hline & & $\mathbf{P}_{11^{*}}$ & 2.80 & & & $P_{112}$ & 2.83 \\
\hline & & $\mathbf{P}_{1 \mathrm{ml}}$ & 2.56 & & & $\mathbf{P}_{1 \mathrm{a} 1}$ & 2.23 \\
\hline & \multirow[t]{4}{*}{5} & $P_{111}$ & 2.23 & & \multirow[t]{4}{*}{10} & $P_{111} *$ & 2.53 \\
\hline & & $P_{112}$ & 2.06 & & & $\mathbf{P}_{\mathrm{m} 11}$ & 2.50 \\
\hline & & $\mathbf{P}_{1 \mathrm{a} 1}$ & 2.53 & & & $P_{112}$ & 2.50 \\
\hline & & $\mathbf{P}_{1 \mathrm{~m} 1^{*}}$ & 3.06 & & & $P_{1 a 1}$ & 2.43 \\
\hline
\end{tabular}

*Selected arrangements 
Table.4 Weighted mean scores for selected border arrangements in different colour schemes $\mathrm{n}=30$

\begin{tabular}{|c|c|c|c|c|}
\hline Design No. & $\begin{array}{c}\text { Border } \\
\text { arrangements }\end{array}$ & $\begin{array}{l}\text { Weighted Mean } \\
\text { Score }\end{array}$ & Colour scheme selected & Coloured Border arrangement \\
\hline 1. & $\mathrm{P}_{1 \mathrm{~m} 1}$ & 4.10 & $\begin{array}{c}\text { Complementry } \\
\text { Colours (red-green) }\end{array}$ &  \\
\hline 2. & $\mathrm{P}_{1 \mathrm{a} 1}$ & 4.16 & $\begin{array}{c}\text { Complementry } \\
\text { Colours (red-green) }\end{array}$ & \\
\hline 3. & $\mathrm{P}_{1 \mathrm{~m} 1}$ & 4.03 & $\begin{array}{c}\text { Complementry } \\
\text { Colours (red-green) }\end{array}$ & \\
\hline 4. & $\mathrm{P}_{1 \mathrm{a} 1}$ & 4.40 & $\begin{array}{c}\text { Complementry } \\
\text { Colours (red-green) }\end{array}$ & \\
\hline 5. & $\mathrm{P}_{1 \mathrm{~m} 1}$ & 4.10 & $\begin{array}{l}\text { Monochromatic colour } \\
\text { (blue) }\end{array}$ & \\
\hline 6. & $\mathrm{P}_{\mathrm{m} 11}$ & 4.16 & $\begin{array}{c}\text { Complementry } \\
\text { Colours (blue-orange }\end{array}$ & \\
\hline 7. & $\mathrm{P}_{111}$ & 4.20 & $\begin{array}{c}\text { Complementry } \\
\text { Colours (blue-orange) }\end{array}$ & \\
\hline 8. & $\mathrm{P}_{\mathrm{m} 11}$ & 4.33 & $\begin{array}{l}\text { Monochromatic colour } \\
\text { (red) }\end{array}$ & \\
\hline 9. & $\mathrm{P}_{\mathrm{m} 11}$ & 4.00 & $\begin{array}{c}\text { Complementry } \\
\text { Colours (blue-orange) }\end{array}$ & \\
\hline 10. & $\mathrm{P}_{111}$ & 3.93 & $\begin{array}{l}\text { Monochromatic colour } \\
\text { (red) }\end{array}$ & \\
\hline
\end{tabular}


Table.5 Graphical representations of the aipan designs

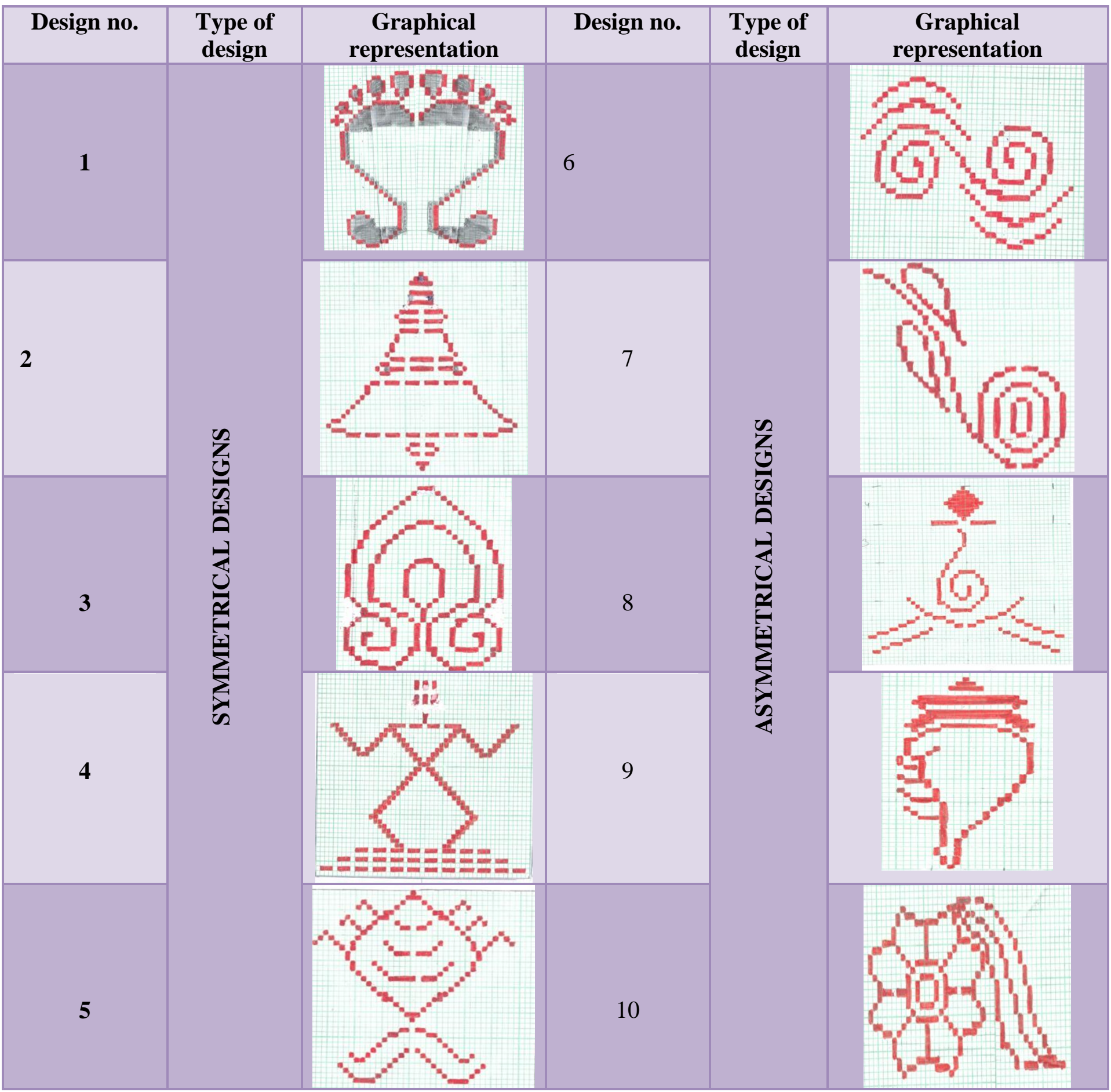

\section{Graphical representation of aipan designs}

The graphical representation of the aipan designs reveals the possibility of weaving border through both simple hand loom as well as jacquard loom in cotton, wool and silk yarn for application on handloom and handicraft textile products prevalent among artisans 
based in state. Table 5 shows the graphical representations of the aipan designs.

In conclusion, Aipan designs are used to decorate the floor, walls etc. of the houses in Kumaun region of Uttarakhand. Each aipan has its social religious and cultural significance. Aipan designs can be adapted easily for their application in development of border arrangements. Corel Draw X7 software enabled adaptation of selected aipan designs, application of adapted designs into border arrangements and replication of border arrangements in different colour schemes through use of tools present in its menus. It made the tasks easier as well as less time consuming. The selected border arrangements can be woven in any basic weave using graph forms of the adapted design by extra yarn figuring technique of weaving.

The woven borders can be further applied in apparel and accessory articles as yoke, panel or borders at the hemlines. Thus the attempt on adoption among rural artisans could create a new range of products having aipan designs that would be step towards preserving the folk art of state.

\section{References}

Arya, A.; Gahlot, M. and Rani, A. 2017. Adaptation of Aipan designs (A floor art of Uttarakhand) for designing of saree. International Journal of Applied Research. 9 3(7): 737-743.

Arya, A., Rani, A.; and Gahlot, M. 2012. Keeping Tradition Alive in Advancing Society. Saarbrucken, Germany LAP LAMBERT Academic Publishing Gmbh \& Co. KG. pp 171.

Arya, A.; Anita Rani and Gahlot, M. 2011. Redesigning Traditional Pichhora: Approach for the new market trends. Journal of Family Ecology. 6(2): 7579.
Bhatnagar, P. 2005. Decorative design history in Indian textiles and costumes. Chandigarh, Abhishek Publication. pp. 20-31

Gahlot, M. and Naik, S. 2014. Principles of design and application course developed under e- home science courseware consortium project, ICAR, New Delhi.

Gillow, J. and Barnard, N. 1991. Traditional Indian textiles. London, Hudson Ltd. pp. 1-2.

Kumari, P. 2013.Designing of curtains using aipan motifs through printing. Thesis, M.Sc. G. B. Pant University of Agriculture and Technology, Pantnagar.

Negi M. and Rani, A. 2016. New Prospects for Women Empowerment through Value Addition of Remnant Fabrics with Aipan Applique. Indian Research Journal of Extension Education. 16 (3): 84-88.

Negi, M.; Rani, A. and Singh, A. 2015. New horizon for Aipan (Folk art of Uttarakhand) motifs through appliqué. International Journal of ResearchGranthaalayah. 3(9): 36-48.

Negi, M.; Rani, A.; Bala, R. and Singh, A. 2017. New perspective in textile designing with aipan design through tie and dye technique. Chapter in book - Gupta, T.; Mistry, B. and Gupta, B. S. A treatise on Recent Trends and Sustainability in Crafts \& Design. Ed. Jaipur, Indian Institute of Crafts \& Design and New Delhi, Excel India Publishers. pp 113-117.

Sah, V. N. 2006. Aipan: Cultural motifs of Kumaon. Nainital, Ganodaya Prakashan. pp. 20-22.

Sangama, E. M. and Rani, A. 2012. Development of designs for textile designing. Textile Trends. 55(3): 29 33.

Singh, A.; Gahlot, M. and Rani, A. 2013. 
Giving a new dimension to Chikankari: An amalgamation of Aipan and Chikankari. Saarbruken, Germany, LAP LAMBERT Academic Publishing.
Vedika; Grover, E. and Paul, S. 2014.Adaptation of Warli art for the development of blocks for printing of apparels. Asian Journal of Home Science. 9(2): 417-421.

\section{How to cite this article:}

Vandana Bhandari, Anita Rani, Manisha Gahlot and Sakshi. 2019. Aipan: An Inspiring Folkart for Textile Designing. Int.J.Curr.Microbiol.App.Sci. 8(06): 527-537.

doi: https://doi.org/10.20546/ijcmas.2019.806.061 